\title{
Systematic review and meta-analysis: transplanted hematopoietic stem cells and killer cells on leukemia
}

\author{
Yunjie Zhang, Yanping Song, Qingren Ni, Guang Li, Jinqian Dai, Menyun Zhang, Jia Xie \\ Institute of Hematology, Xi'an Jiaotong University Affiliated to Xi'an Central Hospital, Xi'an, China \\ Contributions: (I) Conception and design: Y Zhang, J Xie; (II) Administrative support: Y Song, Q Ni; (III) Provision of study materials or patients: Y \\ Zhang, Y Song, Q Ni, G Li, J Dai; (IV) Collection and assembly of data: All authors; (V) Data analysis and interpretation: G Li, J Dai, M Zhang, J \\ Xie; (VI) Manuscript writing: All authors; (VII) Final approval of manuscript: All authors. \\ Correspondence to: Jia Xie. Institute of Hematology, Xi'an Jiaotong University Affiliated to Xi'an Central Hospital, 161 Xiwu Road, Xincheng District, \\ Xi'an 710003, China. Email: xiejia1232021@163.com.
}

\begin{abstract}
Backgroundk meta-analysis was performed to study the therapeutic effect of hematopoietic stem cell transplantation combined with killer cells (important immune cells of the body) on leukemia, hoping to enhance the postoperative therapeutic efficiency.

Methods: literatures were searched with "Hematopoietic stem cell transplantation", "killer cell", "leukemia", "Cytokine induction", etc. as search terms using Boolean logic search. Review Manager was utilized for meta-analysis after literature screening.

Results: eleven literatures were included, most of which were of low-risk bias (medium-high quality). Through meta-analysis, statistical heterogeneity was found in non-recurring mortality (NRM) between control group and experimental group $\left(\mathrm{Chi}^{2}=15.69, \mathrm{I}^{2}=62 \%, \mathrm{P}=0.02\right)$. The leukemia-free survival rate between two groups was not heterogeneous $\left(\mathrm{Chi}^{2}=13.16, \mathrm{I}^{2}=32 \%, \mathrm{P}=0.16\right)$, without considerable difference between groups $(\mathrm{Z}=1.52, \mathrm{P}=0.13)$. The incidence of graft-versus-host disease (GvHD) between the two groups was statistically heterogeneous $\left(\mathrm{Chi}^{2}=21.38, \mathrm{I}^{2}=67 \%, \mathrm{P}=0.003\right)$. The incidence of graft-versus-host disease in experimental group was greatly inferior to controls $(\mathrm{Z}=3.87, \mathrm{P}=0.0001)$.

Discussion: hematopoietic stem cell transplantation combined with killer cells can effectively reduce the incidence of GvHD after stem cell transplantation in patients. The prognosis of transplantation was good, and it had no obvious effect on the overall survival rate and recurrence rate.
\end{abstract}

Koywords: Hematopoietic stem cell transplantation; killer cells; graft-versus-host disease (GvHD); leukemia

Submitted May 12, 2021. Accepted for publication Jun 25, 2021.

doi: 10.21037/apm-21-1359

View this article at: https://dx.doi.org/10.21037/apm-21-1359

\section{Introduction}

Bone marrow is the main organ of the human body that exercises the hematopoietic function. The normal division and differentiation of hematopoietic stem cells (HSCs) in the bone marrow form various blood cells and lymphocytes (1). Leukemia is caused by the failure of some HSC that should differentiate into blood cells and lymphocytes normally, which instead perform malignant proliferation and accumulation in bone marrow and other tissues, invading the liver, spleen, lymph nodes, and so on.
The malignant disease of hematopoietic tissue formed by the inhibition of normal hematopoietic function is also called "blood cancer" $(2,3)$. The pathology of leukemia is mainly manifested by a decrease in the production of red blood cells, which leads to abnormal changes in the quality and quantity of white blood cells, and an abnormal increase in their number. It also causes infiltration into various organs and systems of the human body which damages the normal function of those organs $(4,5)$. According to its onset and cell morphology, leukemia is classified as either acute or chronic. The main types of leukemia are acute lymphocytic, 
acute myeloid, chronic lymphocytic, and chronic myeloid; among which, chronic myeloid leukemia accounts for about $70 \%$ of all leukemias $(6,7)$. At present, related studies have found that some risk factors may increase the chance of certain types of leukemia. These risk factors include high-dose radiation exposure, history of radiotherapy and chemotherapy, chromosomal abnormalities related diseases (Down syndrome and so on), and chemicals such as formaldehyde $(8,9)$.

The main purpose of treating leukemia is destroying leukemia cells and restoring the normal hematopoietic function of the bone marrow. Different types of leukemia should be treated with comprehensive consideration of the patient's condition and overall health status $(10,11)$. Usually, chemotherapy, targeted therapy, killer cells (the body's important immune cells, which are not only related to anti-rheumatism, anti-tumor, antiviral infection, and immune regulation, but also involved in the development of hypersensitivity and autoimmune diseases in some cases), and hematopoietic stem cell transplantation were used for treatment (12). Hematopoietic stem cell transplantation (HSCT) is recommended for patients with refractory, recurrent leukemia, and newly diagnosed acute leukemia but with high-risk score and genetic adverse prognostic factors, who are successfully matched with high-dose chemotherapy and transplanted $(13,14)$. In addition, cytokine-induced killer cells also have the effect of clearing residual leukemia and preventing its recurrence with less side effects $(15,16)$. To compare and analyze the therapeutic effect of combined therapy and single therapy on leukemia, the therapeutic effect of hematopoietic stem cells combined with killer cells on leukemia was studied by means of meta-analysis. We present the following article in accordance with the PRISMA reporting checklist (available at https://dx.doi. org/10.21037/apm-21-1359).

\section{Methods}

\section{Literature retrieval}

Boolean logic search was utilized to select related literatures. "Hematopoietic stem cell transplantation", "killer cell", "leukemia", "Cytokine induction", and so on, were set as search terms. The databases of PubMed, Medline, Embase, Chinese Biomedical Literature Database, Chinese National Knowledge Infrastructure (CNKI), Wanfang, VIP, and Google Scholar were searched. The search time was from inception of the database to 30 October 2020. All reference lists included in literature and published reviews were tracked to screen document that was not indexed by the database. The literature quality was assessed using the software Review Manager (RevMan) 5.2 (Copenhagen, Denmark: The Nordic Cochrane Center, The Cochrane Collaboration, 2012). Various search terms were combined freely, and after the literature was determined through multiple searches, the search engine was employed to locate the literature. Moreover, the latest research progress was acquired via contact with experts and researchers in corresponding field.

\section{Inclusion and exclusion criteria of literature}

The inclusion criteria for literature were as follows: (I) participants were patients diagnosed with leukemia, with no restriction on pathological type; (II) interventions for patients: participants in the experimental group received HSC transplantation combined with killer cell therapy; (III) the control group was treated with HSC inhibition/ killer cell therapy alone; (IV) types: randomized clinical trial (RCT), prospective cohort study, and case-control ones.

The exclusion criteria were as follows: (I) participants with a serious infectious or neurological disease; (II) literature without RCT; (III) no available data or incomplete reported data; (IV) overlap of participants or data; (V) duplicate literatures and those with too few experimental samples.

After inclusion and exclusion criteria screening, two senior experts independently screened the abstracts and full texts, and three pre-experiments were conducted before further screening. In the case of disagreement between experts, a consensus was reached after discussion, or it was arbitrated by a third expert.

\section{Quality assessment}

The pathology-controlled studies in the meta-analysis were evaluated by Newcastle-Ottawa Scale (NOS) of the Cochrane Collaborative Network. The star system (full score was 9 stars) was utilized to measure the results of the study subjects, case comparison, and inter-group comparison. Literature with 7 stars or above was deemed as high quality (which means low risk bias). Those with 1 star or less were of low quality (which means high risk bias). Literature with 2 to 6 stars was of medium quality (which means medium risk bias).

Two experts implemented the quality evaluation of 


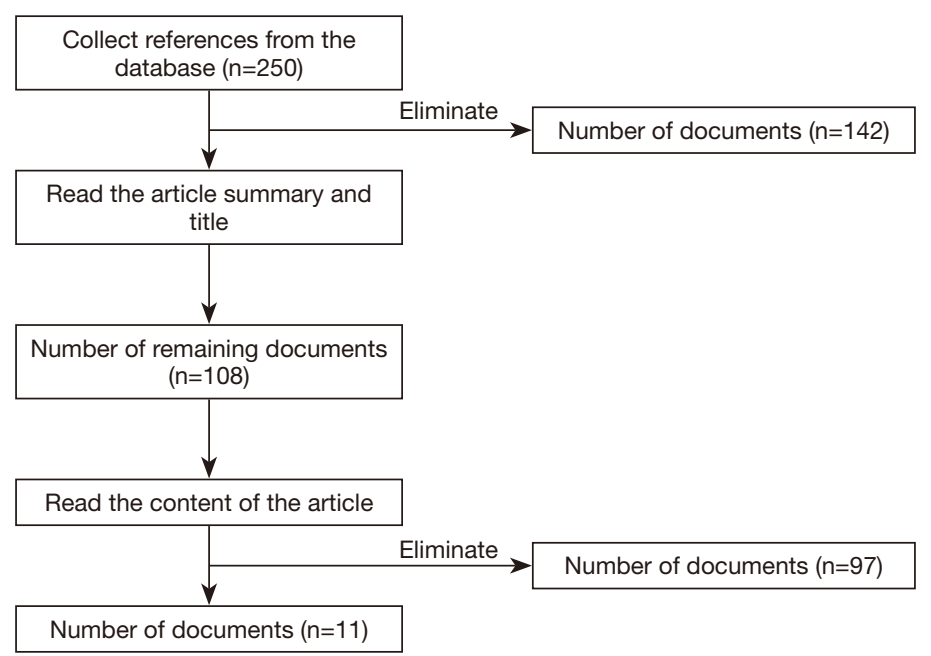

Figure 1 Document retrieval process.

literature independently, and three pre-experiments were required. If there was a disagreement between experts, it was discussed to reach a consensus or was arbitrated by a third party.

\section{Data extraction}

Data was extracted independently by two experts using a unified Excel table, and three pre-experiments were necessary. If there was a disagreement between experts, they can reach a consensus by discussion or ask a third expert to arbitrate. Extracted data included: (I) first author and publication year; (II) number of participants in each groups; (III) grouping of participants and the intervention methods adopted by each group, respectively; (IV) patients' recovery indexes before and after treatment, such as overall survival (OS), cumulative incidence of relapse (CIR), graft-versushost disease (GvHD), leukemia-free survival (LFS), and non-relapse mortality (NRM).

\section{Statistical analysis}

Meta-analysis was performed using RevMan 5.3 (Copenhagen, Denmark: The Nordic Cochrane Center, The Cochrane Collaboration, 2014). Mean difference (MD) or standardized mean difference (SMD) and 95\% confidence interval (CI) were taken as efficacy analysis statistics for study data continuity variables. Included studies were tested for heterogeneity ( $\mathrm{Q}$ test). The bias risk assessment chart of RevMan was utilized to evaluate the risk bias of the included literatures. Each effect was expressed as $95 \%$ CI. When $\mathrm{P}>0.1$ and $\mathrm{I}^{2}<50 \%$, the fixedeffects model (FEM) was employed for meta-analysis. When $\mathrm{P}<0.1$ and $\mathrm{I}^{2}>50 \%$, the random effects model (REM) was utilized.

\section{Results}

\section{Literature collection summary and NOS scale rating}

A total of 250 articles were harvested in this search (Figure 1). We eliminated 142 studies after reading their abstracts and titles and eliminated 97 literatures after reading their full text. Eleven literatures were finally retained for meta-analysis. The main reasons that literatures were excluded included: participants with primary acute or chronic cardiopulmonary dysfunction and mental diseases: 48; literature on animal research: 21; repeated research subjects: 35 ; related information could not be obtained: 66 ; no HSC transplantation or killer cell therapy was performed: 46; and the results lacked raw data: 23. Table 1 shows the information of those studies. The years of included studies covered 2012-2018. The rating results of the NOS scale are shown in Figure 2. There were 5 which scored 7 stars or above, 6 with 2-6 stars, and 0 with 2 stars or below, all of which were medium and high-quality studies.

\section{Assessment on bias risk of included literatures}

The evaluation of multiple risk bias of literatures drawn by Review Manager is shown in Figures 3 and 4. Each 
Table 1 Basic data of included studies

\begin{tabular}{|c|c|c|c|c|c|c|c|c|}
\hline Author & $\begin{array}{l}\text { Published } \\
\text { year }\end{array}$ & Control group & Experimental group & $\begin{array}{c}\text { Number of } \\
\text { participants } \\
\text { (control group) }\end{array}$ & $\begin{array}{l}\text { Number of participants } \\
\text { (experimental group) }\end{array}$ & Parameters & $\begin{array}{c}\text { Gender } \\
\text { (male) }\end{array}$ & $\begin{array}{l}\text { Gender } \\
\text { (female) }\end{array}$ \\
\hline How & 2017 & $\begin{array}{c}\text { Only HSC } \\
\text { transplantation }\end{array}$ & $\begin{array}{l}\text { HSC transplantation } \\
\text { combined with } \mathrm{K} \text { cell }\end{array}$ & 32 & 24 & OS, GvHD, NRM & & \\
\hline Liu & 2018 & Only $\mathrm{K}$ cell & $\begin{array}{l}\text { HSC transplantation } \\
\text { combined with } \mathrm{K} \text { cell }\end{array}$ & 43 & 127 & $\begin{array}{c}\text { OS, CIR, GvHD, } \\
\text { LFS, NRM }\end{array}$ & 93 & 77 \\
\hline Bashey & 2018 & Only $\mathrm{K}$ cell & $\begin{array}{l}\text { HSC transplantation } \\
\text { combined with } \mathrm{K} \text { cell }\end{array}$ & 37 & 33 & $\begin{array}{c}\text { OS, CIR, GvHD, } \\
\text { LFS }\end{array}$ & 37 & 33 \\
\hline Devillier & 2018 & $\begin{array}{c}\text { Only HSC } \\
\text { transplantation }\end{array}$ & $\begin{array}{l}\text { HSC transplantation } \\
\text { combined with } \mathrm{K} \text { cell }\end{array}$ & 31 & 33 & $\begin{array}{c}\text { OS, CIR, GvHD, } \\
\text { LFS }\end{array}$ & & \\
\hline Di Stasi & 2014 & Only K cell & $\begin{array}{l}\text { HSC transplantation } \\
\text { combined with } \mathrm{K} \text { cell }\end{array}$ & 87 & 32 & $\begin{array}{c}\text { CIR, GvHD, LFS, } \\
\text { NRM }\end{array}$ & 68 & 51 \\
\hline Lorentino & 2018 & Only K cell & $\begin{array}{l}\text { HSC transplantation } \\
\text { combined with } \mathrm{K} \text { cell }\end{array}$ & 556 & 74 & LFS & & \\
\hline Santoro & 2018 & $\begin{array}{c}\text { Only HSC } \\
\text { transplantation }\end{array}$ & $\begin{array}{l}\text { HSC transplantation } \\
\text { combined with } \mathrm{K} \text { cell }\end{array}$ & 2,589 & 250 & LFS & 1,627 & 1,208 \\
\hline Cho & 2012 & $\begin{array}{c}\text { Only HSC } \\
\text { transplantation }\end{array}$ & $\begin{array}{l}\text { HSC transplantation } \\
\text { combined with } \mathrm{K} \text { cell }\end{array}$ & 43 & 23 & LFS & 43 & 23 \\
\hline
\end{tabular}

HSC, hematopoietic stem cell; K cell, killer cell; OS, overall survival; CIR, cumulative incidence of relapse; GvHD, graft-versus-host disease; LFS, leukemia-free survival; NRM, non-relapse mortality.

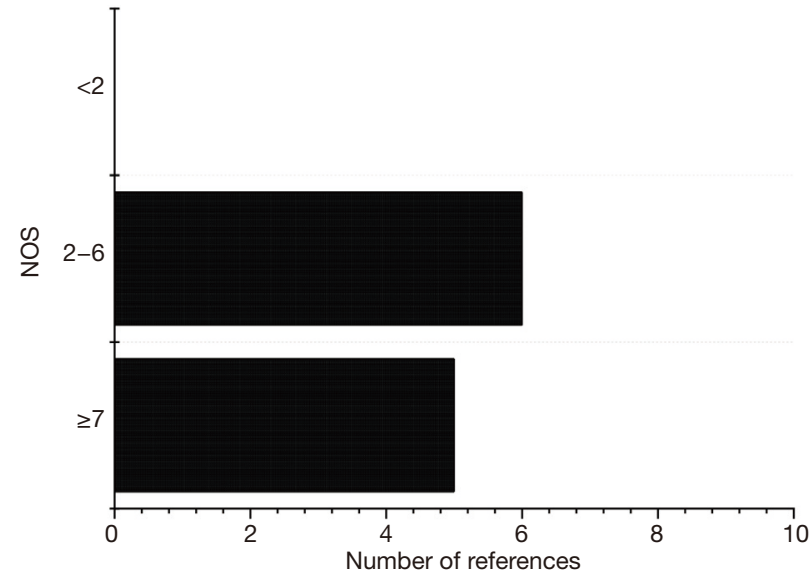

Figure 2 NOS scale rating. NOS, Newcastle-Ottawa Scale. methodological feature of literature was incorporated, and assessment results were input into Review Manager to generate a bias risk map. Random sequence generation (which belongs to selection bias), allocation concealment (which belongs to selection bias), blinding of outcome evaluation (which belongs to measurement bias), incomplete outcome data (which belongs to follow-up bias), and selective reporting (which belongs to reporting bias) were significantly at low-risk bias. Participants' and researchers' blinding (which belongs to implementation bias) and low-risk bias evaluation of other biases were also around $50 \%$. With the exceptions of Devillier [2018] and How [2017], the risk bias of the others was at obviously low risk. 


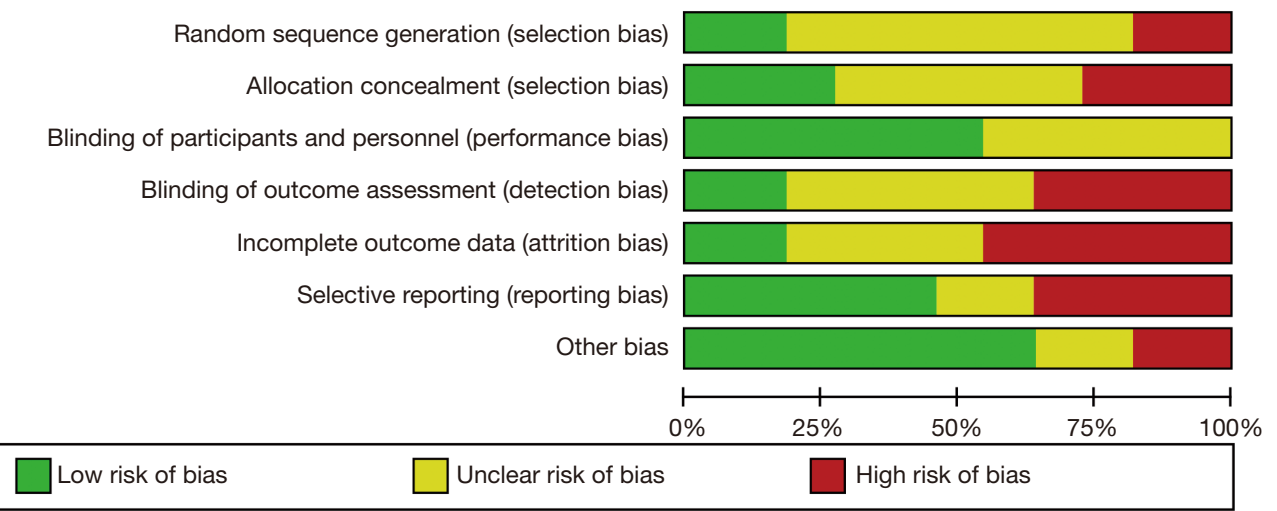

Figure 3 Results of risk bias evaluation of literatures.

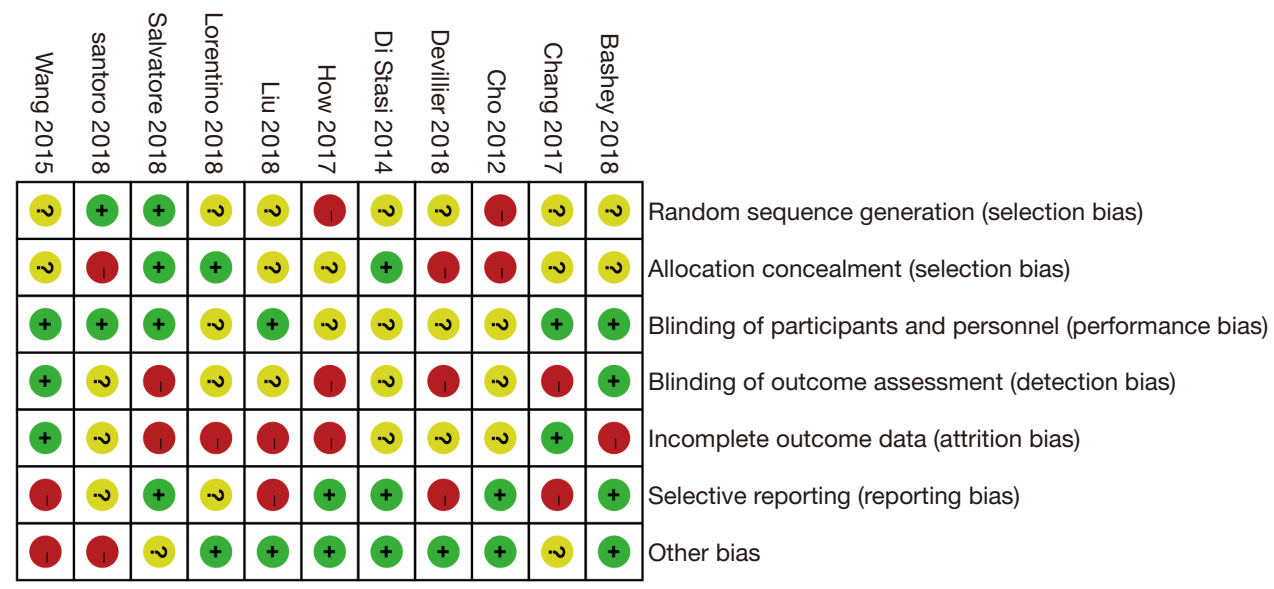

Figure 4 Risk bias assessment of the literatures. Note: green represented "low risk of bias", yellow represented "unclear risk of bias", and red represented "high risk of bias".

\begin{tabular}{|c|c|c|c|c|c|c|c|c|c|}
\hline \multirow[b]{2}{*}{ Study or Subgroup } & \multicolumn{2}{|c|}{ Experimental } & \multicolumn{2}{|c|}{ Control } & \multirow{2}{*}{ Weight } & \multirow{2}{*}{$\begin{array}{l}\text { Odds Ratio } \\
\text { M-H. Fixed, } 95 \% \mathrm{Cl}\end{array}$} & \multirow{2}{*}{\multicolumn{2}{|c|}{$\begin{array}{c}\text { Odds Ratio } \\
\text { M-H. Fixed. } 95 \% \mathrm{Cl}\end{array}$}} & \\
\hline & Events & Total & Events & Total & & & & & \\
\hline Bashey 2018 & 22 & 33 & 23 & 37 & $3.5 \%$ & $1.22[0.46,3.25]$ & & & \\
\hline Chang 2017 & 384 & 498 & 140 & 181 & $23.1 \%$ & $0.99[0.66,1.48]$ & & & \\
\hline Devillier 2018 & 18 & 33 & 16 & 31 & $3.7 \%$ & $1.13[0.42,3.01]$ & & & \\
\hline How 2017 & 9 & 24 & 9 & 32 & $2.4 \%$ & $1.53[0.50,4.75]$ & & & \\
\hline Liu 2018 & 81 & 127 & 27 & 43 & $7.2 \%$ & $1.04[0.51,2.14]$ & & & \\
\hline Salvatore 2018 & 126 & 185 & 1876 & 2469 & $40.9 \%$ & $0.68[0.49,0.93]$ & & & \\
\hline Wang 2015 & 182 & 231 & 180 & 219 & $19.2 \%$ & $0.80[0.50,1.29]$ & & & \\
\hline Total $(95 \% \mathrm{Cl})$ & & 1131 & & 3012 & $100.0 \%$ & $0.85[0.70,1.05]$ & & & \\
\hline Total events & 822 & & 2271 & & & & & & \\
\hline \multicolumn{7}{|c|}{ Heterogeneity: $\mathrm{Chi}^{2}=4.72, \mathrm{df}=6(P=0.58) ; 1^{2}=0 \%$} & 0.05 & 1 & 20 \\
\hline \multicolumn{7}{|c|}{ Test for overall effect: $Z=1.53(P=0.13)$} & Favours [exp & rimental] Favours [c & ontrol] \\
\hline
\end{tabular}

Figure 5 Comparison of OS between two groups of patients. OS, overall survival. 


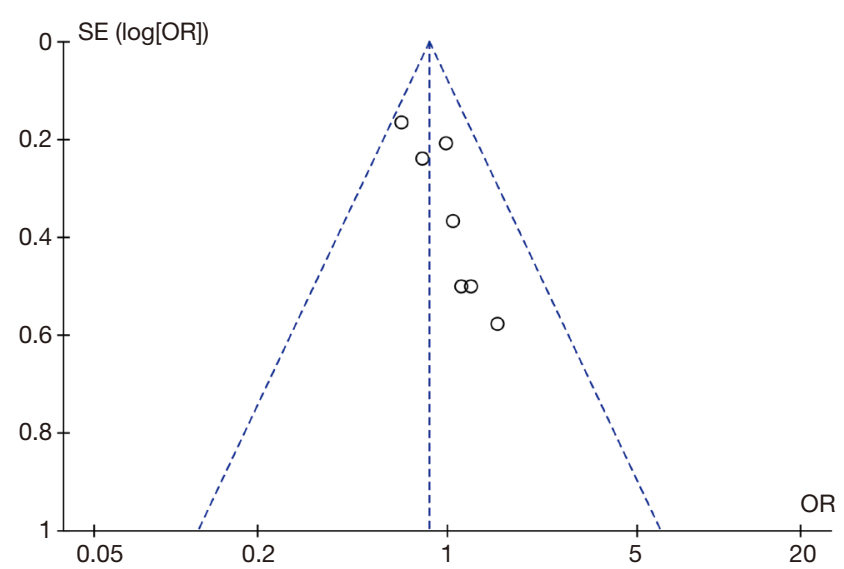

Figure 6 Funnel plot of patients' OS. SE was the standard error; OR was the effect size. OS, overall survival.

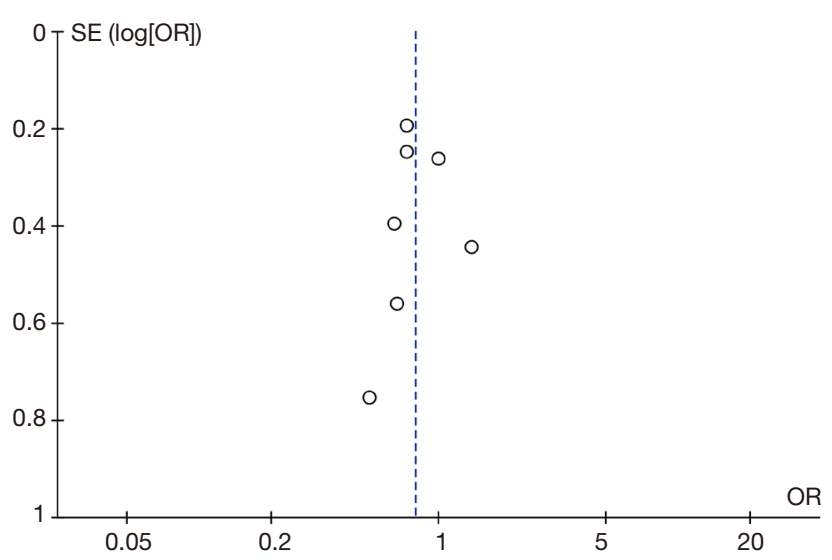

Figure 8 Funnel plot of cumulative recurrence rate.

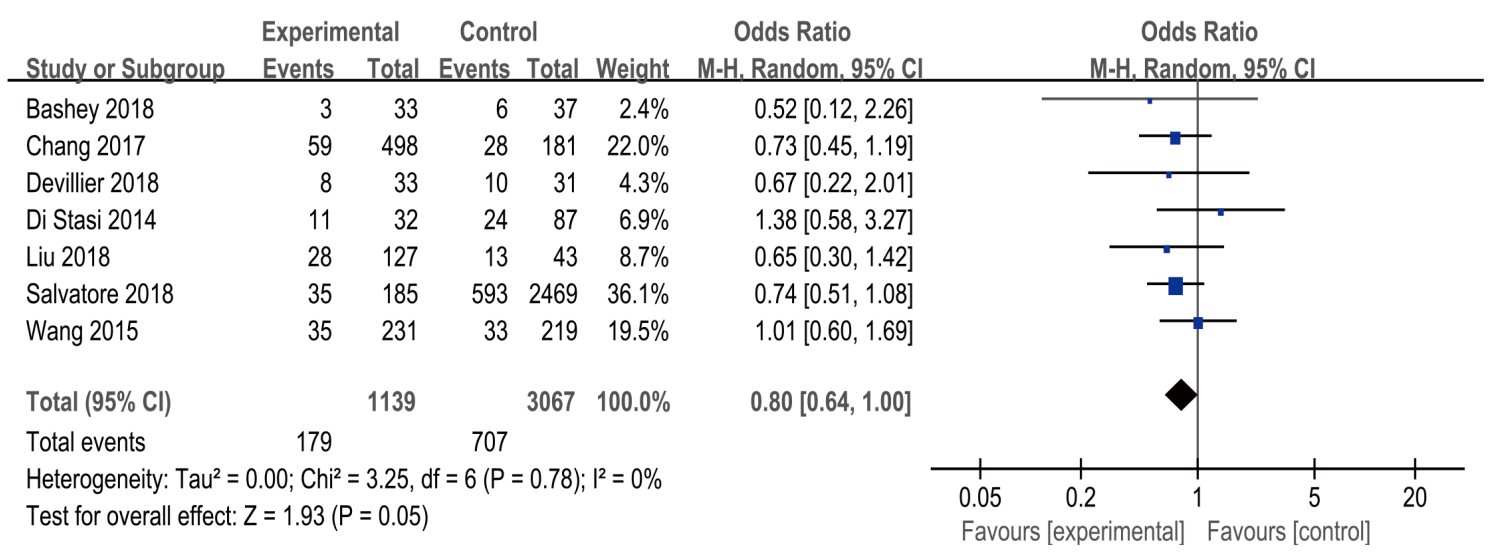

Figure 7 Comparison of cumulative recurrence rate. CI, confidence interval.

\section{Comparison of OS rates between two groups}

Comparison of the OS rate of participants in the control group and the experimental group after treatment is shown in Figure 5. Salvatore's [2018] research results occupied the highest percentage of final combined effects (40.9\%), followed by those of Chang [2017] (23.1\%) and Wang [2015] (19.2\%). Horizontal line (HL) of the $95 \%$ CI of most studies was on the left of invalid vertical line (IVL), and HL crossed the IVL. HL of the $95 \%$ CI fell to the right of IVL in a few studies. Among the 11 studies, a total of 3,012 participants were included in the control groups, and a total of 1,131 participants were included in the experimental groups. No heterogeneity in postoperative speech function was revealed between two groups [chi-square $\left(\chi^{2}\right)=4.72$, $\left.\mathrm{I}^{2}=0 \%, \mathrm{P}=0.58\right]$. The combined effect size (diamond block) was on the left of IVL, odds ratio (OR) was 0.85 , and $95 \%$ CI was $(0.70,1.05)$. FEM was adopted for analysis, and there was no considerable difference in OS rates between the two groups $(\mathrm{Z}=1.53, \mathrm{P}=0.13)$.

The funnel plot of the OS rate comparison is shown in Figure 6. The circles of the included studies were concentrated in the top area, and the research accuracy was high. Although the circles of studies were on both sides of the midline, they were not symmetrical. Therefore, a publication bias was present in the included studies.

\section{Cumulative recurrence rate}

The comparison of cumulative recurrence rates between the control group and the experimental group is displayed in Figure 7. Salvatore's [2018] research results accounted for 


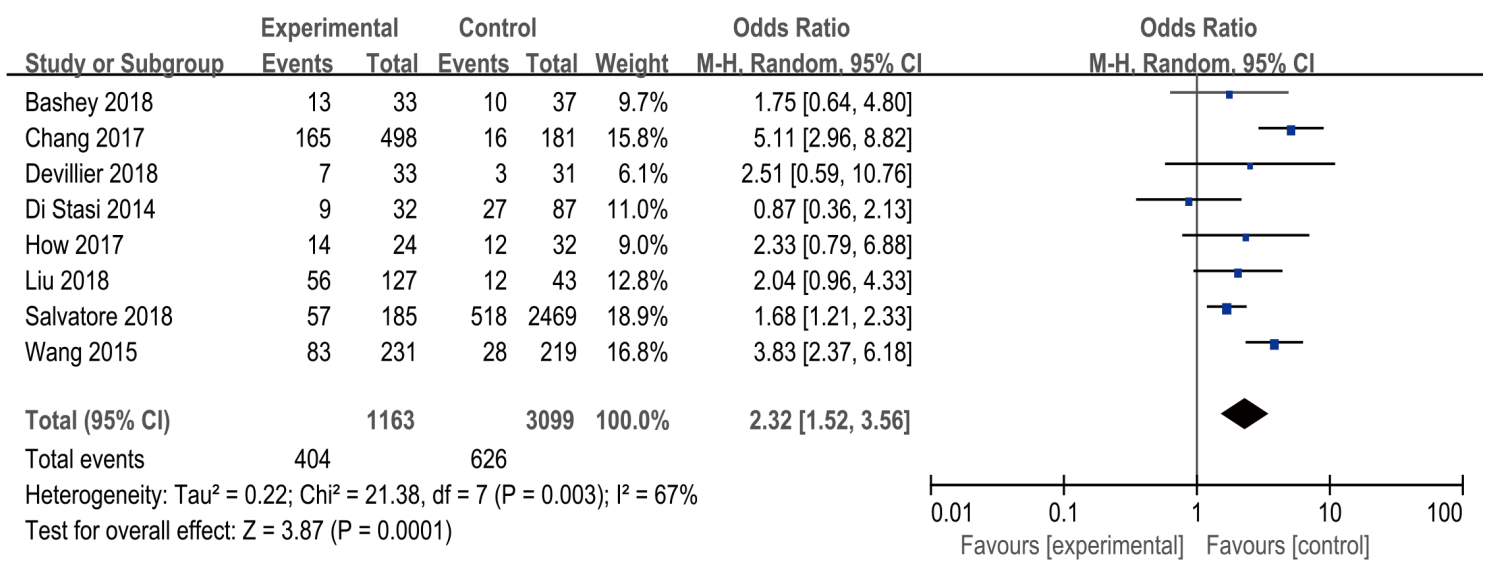

Figure 9 Occurrence of GvHD. GvHD, graft-versus-host disease.

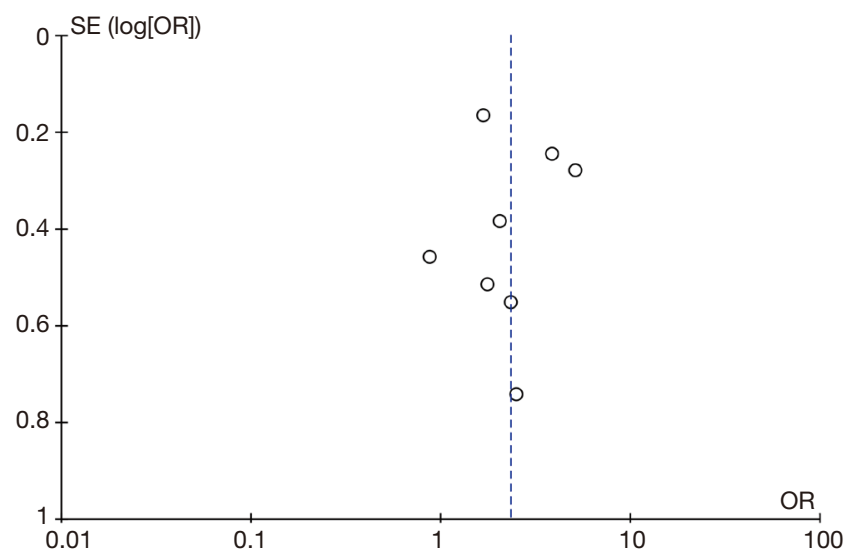

Figure 10 Funnel plot of the occurrence of GvHD. GvHD, graftversus-host disease.

the highest percentage of the final combined results (36.1\%), followed by those of Chang [2017] (22.0\%) and Wang [2015] (19.5\%). In addition, HL of the $95 \%$ CI of most studies was on the left side of IVL, and HL crossed IVL. In a few studies, HL of the $95 \%$ CI fell to the right of IVL. In the included 11 studies, the control groups included a total of 3,067 participants, and the experimental groups included a total of 1,139 participants. The comparison of the cumulative recurrence rate between the control group and the experimental group showed no statistical heterogeneity $\left(\chi^{2}=3.25, \mathrm{I}^{2}=0 \%, \mathrm{P}=0.78\right)$. Diamond block was located to the left of IVL, the OR was 0.80 , and the $95 \%$ CI was 0.64 to 1.00. The random effects model was adopted for analysis, and it was revealed that the difference in cumulative recurrence rate between the two participant groups was not considerable $(\mathrm{Z}=1.93, \mathrm{P}=0.05)$.

A funnel plot of the cumulative recurrence rate is displayed in Figure 8. Although the circles of the included studies were on both sides of the midline but were not symmetrical; therefore, the included studies had publication bias.

\section{The occurrence of GvHD in the two groups}

The comparison of the occurrence of GvHD in the control group and the experimental group after treatment is shown in Figure 9. Salvatore's [2018] research results had the highest percentage of the final combined results (18.9\%), followed by those from Wang [2015] (16.8\%) and Chang [2017] (15.8\%). HL of the 95\% CI of most studies was on right of IVL, and HL crossed IVL. In a few studies, HL of 95\% CI fell to the left of IVL. In the included 11 studies, the control groups included a total 3,099 participants, and the experimental groups included a total of 1,163 participants. Heterogeneity was found in the occurrence of GvHD between groups $\left(\chi^{2}=21.38, \mathrm{I}^{2}=67 \%, \mathrm{P}=0.003\right)$. Diamond block was on the right of IVL, the OR was 2.32, and the $95 \%$ CI was 1.52 to 3.56 . REM was adopted, and the incidence of GvHD in experimental group was vastly inferior to controls $(\mathrm{Z}=3.87, \mathrm{P}=0.0001)$.

The funnel plot of the comparison of the occurrence of GvHD between groups after treatment is displayed in Figure 10. Although the circles of the included studies were found on both sides of the midline, they were not symmetrical. Therefore, there was certain publication bias. 


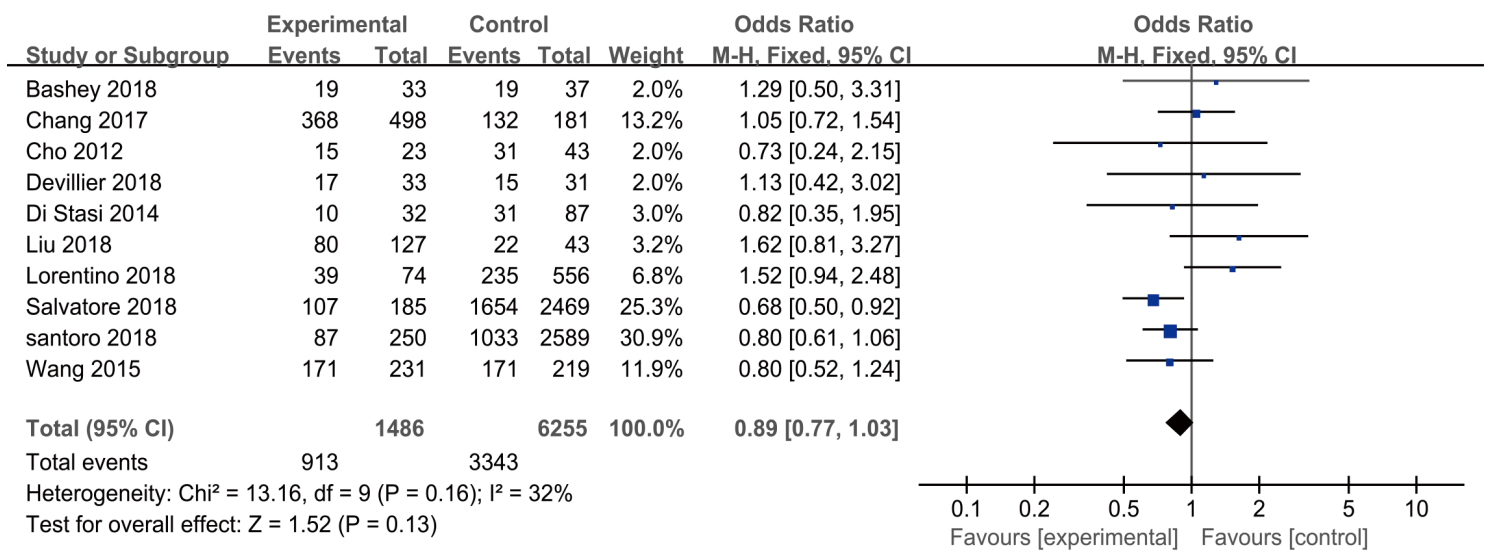

Figure 11 Comparison of LFS rates between the two groups. LFS, leukemia-free survival; CI, confidence interval.

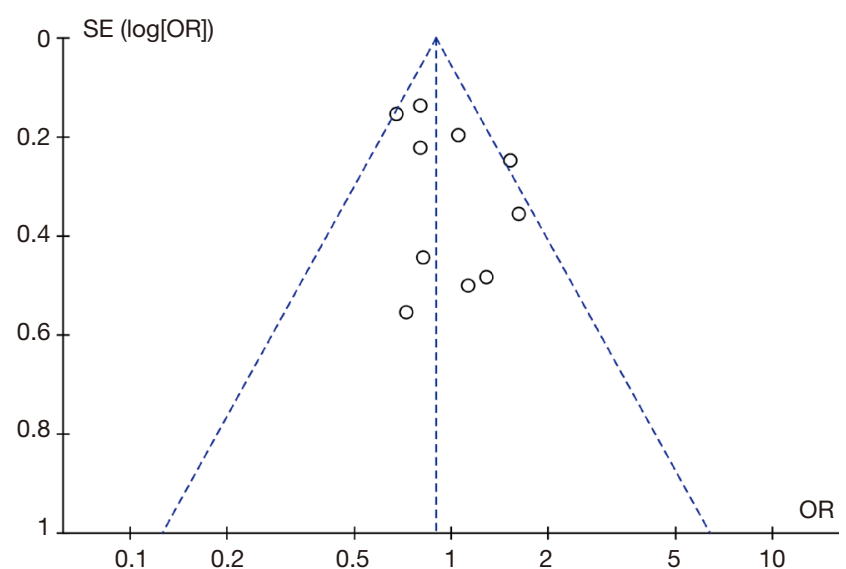

Figure 12 Funnel plot of comparison of LFS. LFS, leukemia-free survival.

\section{Comparison of LFS rates between the two participant groups}

The comparison of LFS rates is shown in Figure 11. The research results of Santoro [2018] occupied the highest percentage of the final combined results $(30.9 \%)$, followed by those of Salvatore [2018] (25.3\%) and Chang [2017] (13.2\%). In addition, in most studies, HL of the $95 \%$ CI crossed IVL. In a few studies, HL of the $95 \%$ CI was on right of IVL. In the included 11 studies, control group included 6,255 participants, while experimental group included a total of 1,486 participants. There was no statistical heterogeneity in the LFS rate between groups $\left(\chi^{2}=13.16\right.$, $\left.\mathrm{I}^{2}=32 \%, \mathrm{P}=0.16\right)$. Diamond block was located to the left of IVL, OR was 0.89 , and $95 \%$ CI was 0.77 to 1.03 . FEM was adopted for analysis, and there was no remarkable difference in LFS rates between the two groups $(\mathrm{Z}=1.52, \mathrm{P}=0.13)$.

A funnel plot showing the comparison of LFS rates between groups is displayed in Figure 12. The circles were concentrated in the top area, and the research accuracy was high. The circles were found on both sides of the midline and were roughly symmetrical. Therefore, the included studies had no publication bias.

\section{Comparison of NRM between the two groups}

The comparison of NRM between the control group and the experimental group is shown in Figure 13. Salvatore's [2018] research results occupied the highest percentage of the final combined effects $(21.9 \%)$, followed by those of Chang [2017], (19.0\%) and Wang [2015] (17.1\%). Moreover, HL of the $95 \% \mathrm{CI}$ of most studies was on right of IVL, and HL crossed IVL. HL of the $95 \%$ CI fell to the left of IVL in some studies. Among the 11 studies included, the control groups included 3,062 subjects, while experimental groups had 1,130 participants. There was statistical heterogeneity in NRM between groups $\left(\chi^{2}=15.69\right.$, $\left.\mathrm{I}^{2}=62 \%, \mathrm{P}=0.02\right)$. Diamond block was on right of IVL, the OR was 1.37 , and $95 \%$ CI was 0.88 to 2.12 . REM was adopted, and there was no substantial difference in NRM between two groups $(\mathrm{Z}=1.40, \mathrm{P}=0.16)$.

A funnel plot comparing the NRM of participants in two groups is shown in Figure 14. Although the circles of the included studies were on both sides of the midline, they weren't symmetrical. Therefore, the included studies had publication bias. 


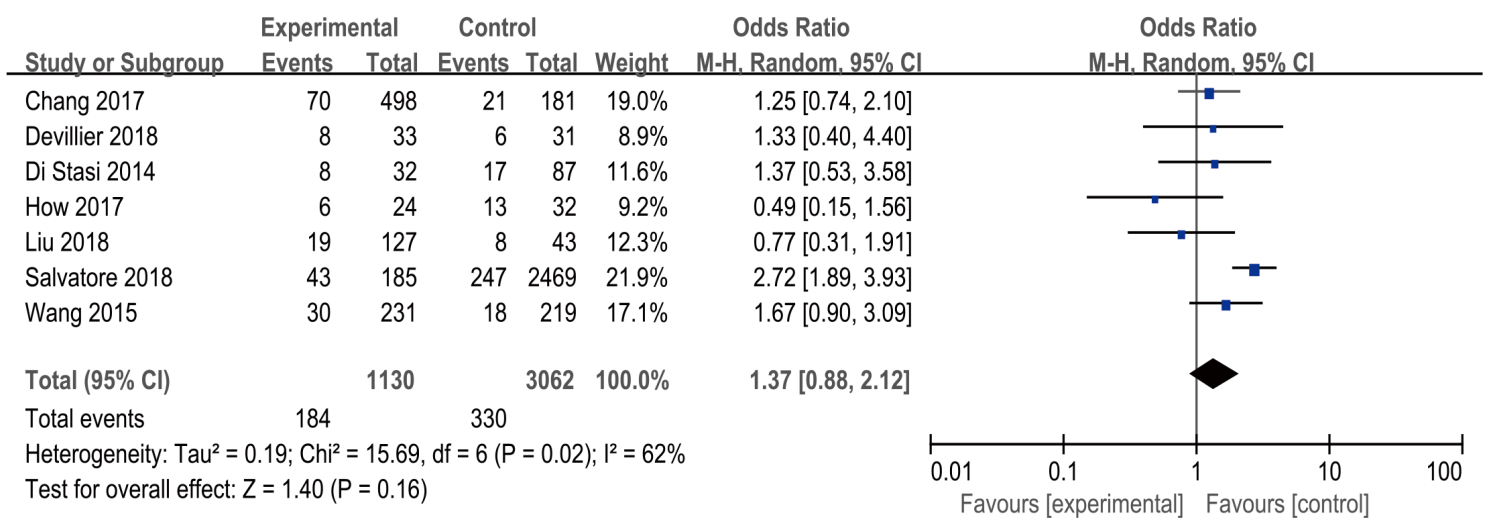

Figure 13 Comparison of NRM between the two groups. NRM, non-relapse mortality.

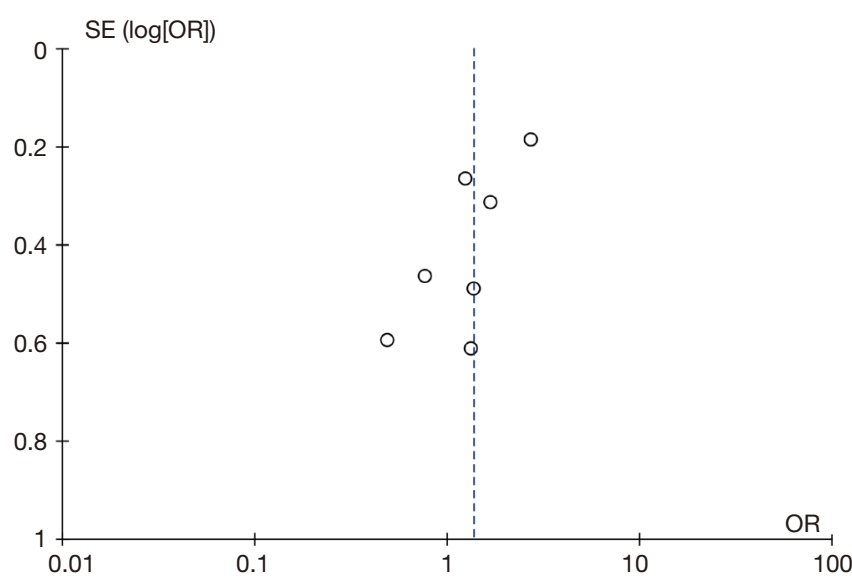

Figure 14 Funnel plot of comparison of NRM. NRM, non-relapse mortality.

\section{Discussion}

Although standardized chemotherapy or hematopoietic stem cell transplantation can significantly improve the treatment effect of leukemia, the recurrence of most patients is still a difficult point in its treatment. Chemotherapy combined with immunotherapy is considered to be the most promising treatment, but the immune escape that easily occurs in the course of immunotherapy has become an important factor affecting the effect of leukemia treatment. Patients with leukemia can only be in complete remission before undergoing an autologous transplant. They then receive chemotherapy to "mobilize" their normal hematopoietic stem cells into the peripheral blood. Their own hematopoietic stem cells are taken and frozen. The patient receives super doses of chemotherapy and radiation to kill the malignant cells in their body. The collected autologous cells are then transfused back to rebuild hematopoietic and immune functions to cure patient $(17,18)$. However, Cooley (19) found that there were very few malignant cells in the bone marrow or peripheral blood during the continuous remission period of leukemia, they could be regarded as "normal" cells, but they were also malignant cells. Therefore, the recurrence rate of autologous transplantation is higher than that of allotransplantation. Allogeneic hematopoietic stem cell transplantation is currently an effective method for the treatment of hematological malignancies, but graft implantation failure is a serious complication of hematopoietic stem cell transplantation. HLA haploidentity is a high risk factor for graft failure. Allogeneic hematopoietic stem cell transplantation plays an important role in killing leukemic cells by eliminating residual leukemic cells. However, HSCT has a high recurrence rate for high-risk patients because it has no GvHD. The killing activity of killer cells against AML cell lines is related to the expression of PD-L1 on the surface of target cells, and the high expression of PD-L1 can inhibit the effective target killing activity of killer cells. Studies suggested that the killer cells have obvious cytotoxic effect on acute myeloid leukemia cells, but have no obvious inhibitory effect on normal bone marrow hematopoietic stem cells, and have high therapeutic performance and safety. Meta-analysis was implemented. Among the 11 included literatures, 9 used randomized control grouping, and only 2 used retrospective analysis, which brought bias to the study. Overall, however, the results of this study were affected slightly. Studies on a single sample can be volatile. 
Meta-analysis was used to carry out quantitative synthesis of all the included literatures in the study, which can not only avoid the differences of different studies due to the sampling from different populations, but also give different weights to the results regarding sample size of each study, so as to increase the sample size and improve the credibility of conclusion. The quality of meta-analysis mainly lies in the authenticity and integrity of the analyzed literature. Due to the objective influence of included literatures, the number of included studies is limited, and the sample size should be expanded in subsequent studies to prevent bias.

The compound logic Boolean logic search method was adopted, and 11 literatures with only HSC transplantation or only $\mathrm{K}$ cell therapy as comparative study were included for meta-analysis, to discuss the therapeutic effect of HSC transplantation combined with $\mathrm{K}$ cell on hematological leukemia. As a result, there was no considerable heterogeneity of speech function between the two groups $\left(\chi^{2}=4.72, \mathrm{I}^{2}=0 \%, \mathrm{P}=0.58\right)$. There was no remarkable difference in OS rate between the 2 participant groups $(\mathrm{Z}=1.53, \mathrm{P}=0.13)$. There was no heterogeneity in the cumulative recurrence rate comparison between the two participant groups $\left(\chi^{2}=3.25, \mathrm{I}^{2}=0 \%, \mathrm{P}=0.78\right)$. The cumulative recurrence rate of participants in experimental group was greatly inferior to controls $(\mathrm{Z}=1.93, \mathrm{P}=0.05)$, indicating that the combined treatment did not have a significant effect on the recurrence rate of patients. Heterogeneity was suggested in the incidence of GvHD between the two participant groups $\left(\chi^{2}=21.38, \mathrm{I}^{2}=67 \%, \mathrm{P}=0.003\right)$. The incidence of $\mathrm{GvHD}$ in the experimental group was greatly inferior to that of controls $(\mathrm{Z}=3.87, \mathrm{P}=0.0001)$. Such results were consistent with the study of Lorentino (20), which indicated that HSC transplantation combined with $\mathrm{K}$ cell can effectively reduce the incidence of stem cell GvHD in patients, the prognosis of transplantation was ideal, and it had no obvious effect on OS and recurrence rate.

\section{Conclusions}

The compound logic Boolean logic search method was adopted, and 11 literatures with only HSC transplantation or only $\mathrm{K}$ cell therapy as comparative study were included for meta-analysis, to discuss the efficiency of HSC transplantation combined with $\mathrm{K}$ cell on hematological leukemia. The results revealed that HSC transplantation combined with $\mathrm{K}$ cell can effectively reduce the incidence of stem cell GvHD in leukemia patients, the prognosis of transplantation was ideal, and it had no obvious effect on the OS and recurrence rates. However, the meta-analysis in this work still had limitations due to various confounding influence factors. The literatures selected were case-control studies. Therefore, there was survival bias itself, and many other indicators may not have been included in the study, which reduces the combined effect size notably. We will implement follow-up analysis of leukemia patients in the future to explore the effect of combined treatment on leukemia patients. In short, this work lays a theoretical basis and data support for the clinical treatment of leukemia and other hematological diseases.

\section{Acknowledgments}

Funding: None.

\section{Footnote}

Reporting Checklist: The authors have completed the PRISMA reporting checklist. Available at https://dx.doi. org/10.21037/apm-21-1359

Conflicts of Interest: All authors have completed the ICMJE uniform disclosure form (available at https://dx.doi. org/10.21037/apm-21-1359). The authors have no conflicts of interest to declare.

Ethical Statement: The authors are accountable for all aspects of the work in ensuring that questions related to the accuracy or integrity of any part of the work are appropriately investigated and resolved.

Open Access Statement: This is an Open Access article distributed in accordance with the Creative Commons Attribution-NonCommercial-NoDerivs 4.0 International License (CC BY-NC-ND 4.0), which permits the noncommercial replication and distribution of the article with the strict proviso that no changes or edits are made and the original work is properly cited (including links to both the formal publication through the relevant DOI and the license). See: https://creativecommons.org/licenses/by-nc-nd/4.0/.

\section{References}

1. Wang Y, Liu QF, Xu LP, et al. Haploidentical vs identicalsibling transplant for AML in remission: a multicenter, 
prospective study. Blood 2015;125:3956-62.

2. Ljungman P, de la Camara R, Robin C, et al. Guidelines for the management of cytomegalovirus infection in patients with haematological malignancies and after stem cell transplantation from the 2017 European Conference on Infections in Leukaemia (ECIL 7). Lancet Infect Dis 2019;19:e260-72.

3. Yaniv I, Krauss AC, Beohou E, et al. Second Hematopoietic Stem Cell Transplantation for PostTransplantation Relapsed Acute Leukemia in Children: A Retrospective EBMT-PDWP Study. Biol Blood Marrow Transplant 2018;24:1629-42.

4. Chang YJ, Wang Y, Liu YR, et al. Haploidentical allograft is superior to matched sibling donor allograft in eradicating pre-transplantation minimal residual disease of AML patients as determined by multiparameter flow cytometry: a retrospective and prospective analysis. J Hematol Oncol 2017;10:134.

5. Wang Z, Li Z, Wu Q, et al. The risk of developing acute non-lymphocytic leukemia in women with breast cancer. Transl Cancer Res 2020;9:2701-9.

6. Czyz A, Nagler A. The Role of Measurable Residual Disease (MRD) in Hematopoietic Stem Cell Transplantation for Hematological Malignancies Focusing on Acute Leukemia. Int J Mol Sci 2019;20:5362.

7. Devillier R, Legrand F, Rey J, et al. HLA-Matched Sibling versus Unrelated versus Haploidentical Related Donor Allogeneic Hematopoietic Stem Cell Transplantation for Patients Aged Over 60 Years with Acute Myeloid Leukemia: A Single-Center Donor Comparison. Biol Blood Marrow Transplant 2018;24:1449-54.

8. Chen XP, Cao ZR, Hu J. Advances in Allogeneic Hematopoietic Stem Cell Transplantation for Chronic Myelogenous Leukemia--Review. Zhongguo Shi Yan Xue Ye Xue Za Zhi 2019;27:1334-8.

9. Liu Y, Huang X, Fei Q, et al. Comparison analysis between haplo identical stem cell transplantation and matched sibling donor stem cell transplantation for high-risk acute myeloid leukemia in first complete remission. Sci China Life Sci 2019;62:691-7.

10. Salvatore D, Labopin M, Ruggeri A, et al. Outcomes of hematopoietic stem cell transplantation from unmanipulated haploidentical versus matched sibling donor in patients with acute myeloid leukemia in first complete remission with intermediate or high-risk cytogenetics: a study from the Acute Leukemia Working Party of the European Society for Blood and Marrow Transplantation. Haematologica 2018;103:1317-28.
11. Gilleece MH, Labopin M, Yakoub-Agha I, et al. Measurable residual disease, conditioning regimen intensity, and age predict outcome of allogeneic hematopoietic cell transplantation for acute myeloid leukemia in first remission: A registry analysis of 2292 patients by the Acute Leukemia Working Party European Society of Blood and Marrow Transplantation. Am J Hematol 2018;93:1142-52.

12. Cho BS, Yoon JH, Shin SH, et al. Comparison of allogeneic stem cell transplantation from familial-mismatched/ haploidentical donors and from unrelated donors in adults with high-risk acute myelogenous leukemia. Biol Blood Marrow Transplant 2012;18:1552-63.

13. Bashey ZA, Zhang X, Brown S, et al. Comparison of outcomes following transplantation with T-replete HLA-haploidentical donors using post-transplant cyclophosphamide to matched related and unrelated donors for patients with AML and MDS aged 60 years or older. Bone Marrow Transplant 2018;53:756-63.

14. Shelikhova L, Ilushina M, Shekhovtsova Z, et al. $\alpha \beta$ T Cell-Depleted Haploidentical Hematopoietic Stem Cell Transplantation without Antithymocyte Globulin in Children with Chemorefractory Acute Myelogenous Leukemia. Biol Blood Marrow Transplant 2019;25:e179-82.

15. Di Stasi A, Milton DR, Poon LM, et al. Similar transplantation outcomes for acute myeloid leukemia and myelodysplastic syndrome patients with haploidentical versus 10/10 human leukocyte antigen-matched unrelated and related donors. Biol Blood Marrow Transplant 2014;20:1975-81.

16. Santoro N, Labopin M, Giannotti F, et al. Unmanipulated haploidentical in comparison with matched unrelated donor stem cell transplantation in patients 60 years and older with acute myeloid leukemia: a comparative study on behalf of the ALWP of the EBMT.J Hematol Oncol 2018;11:55.

17. Okamoto Y, Nakazawa Y, Inoue M, et al. Hematopoietic stem cell transplantation in children and adolescents with nonremission acute lymphoblastic leukemia. Pediatr Blood Cancer 2020;67:e28732.

18. Romee R, Rosario M, Berrien-Elliott MM, et al. Cytokine-induced memory-like natural killer cells exhibit enhanced responses against myeloid leukemia. Sci Transl Med 2016;8:357ra123.

19. Cooley S, He F, Bachanova V, et al. First-in-human trial of rhIL-15 and haploidentical natural killer cell therapy for advanced acute myeloid leukemia. Blood Adv 2019;3:1970-80. 
20. Lorentino F, Labopin M, Bernardi M, et al. Comparable outcomes of haploidentical, 10/10 and 9/10 unrelated donor transplantation in adverse karyotype AML in first complete remission. Am J Hematol 2018;93:1236-44.

(English Language Editor: J. Jones)

Cite this article as: Zhang Y, Song Y, Ni Q, Li G, Dai J, Zhang M, Xie J. Systematic review and meta-analysis: transplanted hematopoietic stem cells and killer cells on leukemia. Ann Palliat Med 2021;10(7):7872-7883. doi: 10.21037/ apm-21-1359 